\title{
Atividade simbólica na perspectiva da abordagem histórico-cultural de Lev S. Vigotski
}

Ruben de Oliveira Nascimento ${ }^{1}$

RESUMO: Este estudo é um trabalho de revisão narrativa da literatura que visa compreender, na perspectiva da abordagem histórico-cultural do psicólogo Lev S. Vigotski, concepção, aspectos básicos e importância da atividade simbólica no desenvolvimento psíquico, cultural e social da criança. Além disso, abordar o tema na aprendizagem da linguagem escrita e da aritmética. $\mathrm{O}$ trabalho comenta a visão de atividade simbólica como mediação cultural no desenvolvimento psicológico da criança, e reflete sobre seus efeitos para a formação humana e na educação escolar.

PALAVRAS-CHAVE: Atividade simbólica. Psicologia histórico-cultural. Vigotski.

\section{Symbolic activities in the perspective of Lev S. Vigotski's historical-cultural approach}

\begin{abstract}
This paper is a narrative review that aims to learn, from the perspective of psychologist Lev S. Vigotski's historical-cultural approach, the conception, basic aspects, and the importance of symbolic activities in the psychological, cultural, and social development of the child. In addition, its goal is to address the topic in the learning of the written language and arithmetic. The work comments on the view of symbolic activities as cultural mediations in the psychological development of the child, and reflects on its effects on human formation and school education.
\end{abstract}

KEYWORDS: Symbolic activities. Historical-cultural psychology. Vigotski.

\footnotetext{
${ }^{1}$ Psicólogo. Doutor em Educação pela Faculdade de Educação da Universidade Federal de Uberlândia (FACED/UFU). Docente do Instituto de Psicologia da Universidade Federal de Uberlândia (IP/UFU). Endereço eletrônico: ruben@ufu.br.
}

\begin{tabular}{|l|l|l|l|l|l|l|} 
APRENDER - Cad. de Filosofia e Psic. da Educação & Vitória da Conquista & Ano XIV & n. 23 & p. 54-71 & & jan./jun.2020
\end{tabular}




\section{Introdução}

A escrita, a leitura e o cálculo são atividades fundamentais na escola, cujo processo requer compreensão intelectual e uso normativo, formal, de símbolos e signos convencionais, ou sistemas de representações, que liberam a criança das restrições da situação imediata, com grande efeito no seu desenvolvimento psicológico e social. Dominar o uso formal de símbolos e signos para representar objetos e ações, é um dos aspectos centrais da educação escolar. Segundo Dupas, Oliveira e Costa (1997, p. 221-222), "símbolos são uma classe de objetos sociais usados para representar alguma coisa e são usados para pensar, comunicar, representar. Ele só é simbólico quando há um significado (uma representação), uma intencionalidade".

Para a Psicologia Histórico-Cultural de Lev S. Vigotski, a escrita, a leitura e o cálculo são exemplos de atividades simbólicas promovidas na escola. Mas Vigotski entende essas aprendizagens escolares como sendo um momento no curso geral do desenvolvimento psíquico da criança, e na sua formação humana. Como o autor discute e define atividade simbólica (e o simbólico), comenta o seu lugar no desenvolvimento das funções psíquicas superiores e analisa seu processo na educação escolar, evidencia fundamentos e ideias básicas de sua psicologia. Por isso, é importante compreender suas discussões e ideias sobre o tema.

Este trabalho é uma revisão narrativa da literatura, que busca identificar com que termos e ideias Vigotski expressa sua compreensão psicológica de atividade simbólica (e o simbólico) no desenvolvimento humano, como define seus aspectos psicológicos básicos e comenta sua importância no desenvolvimento da criança e no processo escolar. Este trabalho não esgota a análise psicológica de tão complexo assunto ou o seu estudo na obra do autor. No âmbito educacional, a ênfase deste trabalho é na aprendizagem da escrita e do cálculo. O percurso do estudo envolveu leitura de textos de Vigotski relacionados ao tema e objetivo propostos, com apontamentos, transcrição de trechos centrais, explicativos, e sistematização de suas ideias, complementando a análise com contribuições de comentadores de sua obra.

\section{Acercando-se do simbólico na abordagem histórico-cultural de Vigotski}

Costa e Martins (2018) comentam que, em seu projeto de psicologia como ciência, Vigotski busca superar a crise entre a psicologia baseada nas ciências naturais e a perspectiva idealista, no estudo da consciência e do comportamento humano. Costa e Martins (2018) comentam que, como alternativa, Vigotski propõe captar os fenômenos psicológicos em suas formas mais desenvolvidas das funções psíquicas humanas, analisando a interconexão entre mente e cérebro como inscrita e produzida nas relações sociais, utilizando-se da dialética materialista como uma terceira via de análise. Esses autores 
comentam que essa alternativa se constitui com a criação da proposta histórico-cultural, em que Vigotski articula a dimensão biológica com a histórica na compreensão do desenvolvimento humano. Para Costa e Martins (2018, p. 544), "Vigotski não só não negou a mente como acreditava ser possível estudá-la, compreendê-la como expressão da existência histórica e material do homem.”

Sobre o estudo psicológico da consciência, Kozulin (2002) comenta que, para Vigotski, para tornar a consciência um "objeto" de estudo psicológico é preciso um princípio explanatório da consciência, encontrado em outra camada da realidade: a atividade socialmente carregada. Da perspectiva dialética materialista, Cheptulin (2004) comenta:

Não há dúvida de que a consciência está ligada a certos processos que se desenvolvem no cérebro, mas esses processos não têm condições para engendrar a consciência. Para que ela apareça, o ser possuidor de um cérebro deve necessariamente estar incluído em um sistema de relações sociais e agir em comum com outros homens; ou, em outros termos, deve viver uma vida humana, social. (CHEPTULIN, 2004, p. 90).

No tocante ao estudo do desenvolvimento das funções psíquicas elementares, ligadas de modo particular à atividade cerebral (percepção direta, atenção, memória, etc.), em funções superiores, Vigotski defende se tratar de um processo dialético ${ }^{2}$, em que a mediação dos sistemas simbólicos, não limitados a processos cerebrais típicos, tem importante papel. Seus efeitos são percebidos na interação do homem, ou do pensamento humano, com a realidade concreta e o conhecimento. Para Zago (2013, p. 117):

Atingir o concreto pelo pensamento, através da mediação, não significa aderir ao idealismo. O método materialista histórico dialético postula que apesar de o conhecimento ser construído pelo pensamento ele ainda assim é social, e, quando o processo é feito de forma correta, um reflexo da realidade.

Osucci e Saito (2010) comentam que:

as funções psicológicas superiores têm um suporte biológico, mas são produto da atividade cerebral, que se caracteriza por possuir uma origem social; ou seja, resultam das relações sociais estabelecidas entre os homens e o mundo exterior, na dinâmica do processo histórico, e são mediadas por um sistema simbólico. Essa perspectiva históricocultural possibilita aos sujeitos a realização de ações mentais que ampliam a capacidade de interação dos indivíduos com a realidade objetiva para além da experiência imediata ou da resolução de um problema concreto e prático. (OSUCCI; SAITO, 2010, p. 7-8)

$\mathrm{Na}$ abordagem de Vigotski, sistemas simbólicos marcam também a relação que o autor estabelece entre o biológico e o cultural. Na análise de Pino (2005), em Vigotski, isso significa falar de uma relação

\footnotetext{
${ }^{2}$ Vygotski (1995a) comenta que as funções elementares (atenção, percepção, memória etc.) não ficam apartadas nas funções psíquicas desenvolvidas num nível superior, intencional, voluntário e consciente (atenção voluntária, percepção mediada, memória lógica etc.). Para o autor, as funções psíquicas elementares se encontram subordinados de alguma forma nessa complexa passagem para um nível superior de conduta, baseado na ideia de que "a etapa anterior não desaparece quando nasce a etapa nova, mas é superada pela nova, é dialeticamente negada por ela, é transladada para ela e existe nela" (VYGOTSKI, 1995a, p. 145, tradução nossa, livre).
} 
em que o biológico sob a ação do cultural adquire uma dimensão simbólica e uma nova forma de existência.

De acordo com Pino (2005), a vertente histórico-cultural de Vigotski coloca que o ser humano, como ser biológico provido de um sistema nervoso complexo, pode perceber, diferenciar e associar coisas, captar sinais do ambiente que permitem orientar suas ações, e também se expressar, interagir. Mas é próprio do homem também "conferir a todas essas funções uma significação, o que dá às atividades biológicas uma dimensão simbólica” (p. 54, grifo do autor).

Segundo Pino (2005), atribuir significado a coisas e a essas funções não destitui a condição natural do homem e não destitui das coisas sua condição material, mas as tornam em coisas e funções humanas, atribuindo-se significação às coisas que o homem encontra prontas na natureza ou as que ele produz agindo sobre elas. Pino (2005) comenta que os símbolos são meios da produção cultural humana, em que as ideias procuram uma forma material de expressão socialmente e historicamente desenvolvida pela humanidade. Para ele, desse modo, confere-se à matéria uma forma simbólica e ao simbólico uma forma material.

Mas Pino (2005) chama atenção de que, mesmo adquirindo-se o simbólico, a natureza continua sendo uma realidade "natural", no sentido de que é preciso formar alguma articulação com a atividade cerebral, uma vez que as funções psíquicas superiores pressupõem, necessariamente, uma base biológica, uma ordem natural. Pino (2005) assinala que, para Vigotski, a ruptura com o natural se dará com o emprego do signo influindo nos processos psíquicos elementares, e os transformando. Vygotski (1995a) comenta que no processo da vida social o homem criou sistemas complexos de simbolização historicamente desenvolvidos, conferindo significado às suas ações com a ajuda dos signos. Para Eagleton (2005, p. 141) "é o signo que abre aquela distância operativa entre nós mesmos e nossos arredores materiais e que nos permite transformá-los em história".

$\mathrm{Na}$ análise de Martins (2011), Vigotski não estava simplesmente fracionando a natureza humana em elementos naturais e culturais, mas frisando as contradições entre essas formas no desenvolvimento humano. Para Martins (2011, p. 217-218):

a tese defendida por esse autor consiste em que a lei fundamental do desenvolvimento humano, o que move o seu curso, radica nas contradições que são instaladas entre processos biológicos e culturais. Tais contradições, por sua vez, são instaladas, isto é, provocadas pela vida social à medida da apropriação dos signos da cultura.

Para Vygotski (1995b), essas questões envolvem ver o conceito de desenvolvimento humano não como um fenômeno puramente quantitativo e natural, mas pensá-lo no plano do desenvolvimento cultural, e enfocar historicamente as formas superiores de conduta.

Vygotski (1995c) comenta que os estudos tradicionais de desenvolvimento das funções psíquicas superiores, que coloca o foco em sua faceta natural são, antes de tudo, errôneos e unilaterais, por não 
verem como fatos do desenvolvimento histórico e por não compreenderem a natureza dos fenômenos que estudam: "os julga unilateralmente como processos e formações naturais, confundindo o natural e o cultural, o natural e o histórico, o biológico e o social no desenvolvimento da criança" (VYGOTSKI, 1995 c, p. 12) ${ }^{3}$.

Segundo Pino (2005, p. 147), “transformar a natureza em cultura é produzir nela mudanças que, na sua materialidade, veiculem uma ideia ou significação, de maneira que possa ser pensada e comunicada". Nessa análise, Pino (2005) menciona a colocação de Vigotski de que a cultura não cria nada, e sim transforma ${ }^{4}$.

Vygotski (1955b) comenta que são momentos importantes no desenvolvimento das funções psíquicas superiores: "a linguagem e o desenho infantil, o domínio da leitura e da escrita, a lógica da criança e sua concepção do mundo, o desenvolvimento da representação e das operações numéricas, incluindo a psicologia da álgebra e da formação de conceitos" (VYGOTSKI, 1995c, p. 12)5. Em relação às pesquisas sobre esses assuntos, Vygotski (1995c) comenta que, apesar destes exemplos serem processos e objetos modelo nas investigações específicas sobre o desenvolvimento das funções psíquicas, são estudados somente desde o ponto de vista dos processos naturais que os formam e os integram.

\section{Concepção psicológica, caracterização e desenvolvimento da atividade simbólica}

Segundo Vygotski e Luria (2007), a inclusão de operações simbólicas cria um campo psíquico com uma composição totalmente nova e livre da situação imediata. Para os autores, esse processo de inclusão remete a um longo percurso de desenvolvimento do simbólico, na criança.

Segundo Kozulin (2002), para Vigotski, fenômenos como o gesto representacional, o simbolismo na brincadeira, o desenho, são como passos no processo de controlar o simbolismo e o caráter convencional do signo, percebidos como importantes características da atividade humana direcionadas pelas relações sociais, segundo as linhas da matriz sociocultural. Para Kozulin (2002), a noção psicológica de atividade, em Vigotski, é percebida como sendo a atualização da cultura no indivíduo, plasmada na função simbólica. Nesse processo, a linguagem marca a atividade da criança e estrutura sua experiência.

Sobre o desenvolvimento de atividades simbólicas, em Vygotski e Luria (2007) lemos o seguinte:

Se reconhecermos o papel dos signos no desenvolvimento das funções psíquicas superiores, será uma consequência lógica incorporar ao sistema funcional formas simbólicas externas, como são a comunicação verbal, a leitura, a escrita, o cálculo ou o desenho. Esses processos têm sido considerados tradicionalmente como auxiliares em relação aos processos psíquicos internos, e alheios a eles. No entanto, da nossa

\footnotetext{
3 Tradução nossa, livre, de: “(...) los enjuicia unilateralmente como procesos y formaciones naturales, confundiendo lo natural y lo cultural, lo natural y lo histórico, lo biológico y lo social en el desarrollo del niño" (VYGOTSKI, 1995c, p. 12).

4 "La cultura no crea nada, tan sólo modifica las aptitudes naturales en concordancia con los objetivos del hombre". (VYGOTSKI, 1995b, p. 152).

${ }^{5}$ Tradução nossa, livre, de: “(...) el lenguaje y el dibujo infantiles, el dominio de la lectura y de la escritura, la lógica del niño y su concepción del mundo, el desarrollo de la representación y de las operaciones numéricas, incluso la psicología del álgebra y de la formación de conceptos" (VYGOTSKI, 1995c, p. 12).
} 
perspectiva, pensamos que eles devem ser incluídos com a mesma classificação que os demais, no sistema de funções psíquicas superiores. Nossa posição é considerá-las fundamentalmente como formas específicas de comportamento construídas no processo de desenvolvimento sociocultural da criança, que compõem a linha externa de desenvolvimento da atividade simbólica, que coexiste com a linha interna, representada pelo desenvolvimento cultural de construções tais como a inteligência prática, a percepção e a memória. (VYGOTSKI; LURIA, 2007, p. 48)

Essa citação mostra partes importantes no desenvolvimento de atividades simbólicas: a) a comunicação verbal, a leitura, a escrita, o cálculo, o desenho, são formas simbólicas externas, específicas, construídas no processo de desenvolvimento social e cultural da criança, compreendendo a linha externa de desenvolvimento da atividade simbólica; b) a linha interna compreende o desenvolvimento cultural da inteligência prática, da percepção, da memória; c) os processos simbólicos externos não são meros meios auxiliares dos processos psíquicos, internos, nem alheios a eles.

Essa citação aponta também para dois fatores centrais, que enriquecem as partes anteriormente destacadas: 1) a linha externa da atividade simbólica coexiste com a linha interna, ou com os processos psíquicos, internos; 2) se as linhas coexistem (existir junto ou simultaneamente) não são indiferentes uma à outra, ou que representem formas separadas.

Segundo Pino (2005), Vigotski não trata de forma separada a atividade prática inteligente e o desenvolvimento de operações simbólicas, afirmando que a união da atividade prática com o signo constitui um grande momento do desenvolvimento intelectual da criança. Para Pino (2005), este desenvolvimento não se trata de um processo puramente natural ou resultado do hábito, mas de um processo enraizado profundamente no desenvolvimento da criança, em que sua história individual se liga completamente à sua história social.

Para avançar nessas questões, é preciso considerar a mediação semiótica. Pino (2005) comenta que a mediação semiótica trabalhada por Vigotski não está ligada a razões linguísticas ou cognitivas, ou sofre essa influência: "ele fala do signo linguístico não como um linguista, mas como pensador da natureza simbólica do homem" (PINO, 2005, p. 135).

Segundo Pino (2005), Vigotski está buscando uma explicação para a natureza social e cultural das funções mentais superiores com base no materialismo histórico e dialético, e a encontra na mediação semiótica, conferindo ao signo um valor psicológico instrumental equivalente ao que desempenha o instrumento técnico na relação do homem com a natureza. Mas Pino (2005) comenta que o paralelismo

\footnotetext{
${ }^{6}$ Tradução nossa, livre, de: "Se reconocemos el papel de los signos en el desarrollo de las funciones psíquicas superiores, será una consecuencia lógica el incorporar al sistema funcional formas simbólicas externas de actividad, como son la comunicación verbal, la lectura, la escrita, el cálculo o el dibujo. Estos procesos han sido considerados tradicionalmente como auxiliares respecto de los procesos psíquicos internos y ajenos a ellos. Sin embargo, desde la perspectiva que hemos seguido, pensamos que deben ser incluídos con el mismo rango que los demás en el sistema de funciones psíquicas superiores. Nuestra posición es considerarlos fundamentalmente como formas específicas de comportamiento construidas en el proceso de desarrollo sociocultural del niño que conforman la línea externa de desarrollo de la acitividad simbólica que coexiste con la línea interna, que está representada por el desarrollo cultural de construcciones tales como la inteligencia práctica, la percepción y la memoria." (VYGOTSKI; LURIA, 2007, p. 48).
} 
entre signo e instrumento como mediação vai mais além, pois quem usa uma ferramenta de trabalho imprime à sua ação uma significação. Segundo Pino (2005), Vigotski vê essa significação inicialmente na criação e uso do signo como um estímulo artificial que permite ao ser humano controlar sua própria conduta, e mais adiante em sua obra, desenvolve essa explicação na análise das relações genéticas e funcionais entre pensamento e fala. Para Pino (2005, p. 137), Vigotski procura mostrar que o caráter humano da atividade depende da transformação que a palavra opera nela ${ }^{7}$.

Em sua perspectiva histórico-cultural, Vigotski situa a atividade simbólica na experiência cultural da criança, e acentua o papel do signo nesse processo. Ao definir experiência cultural como sendo o que a criança assimila do conteúdo dos meios e dos métodos da cultura, Vygotski (1997) menciona como exemplo a linguagem, os símbolos aritméticos etc., comentando que

a criança aprende a usar funcionalmente determinados signos como meios para executar esta ou aquela operação psicológica. Dessa maneira, as formas elementares e primitivas de conduta se convertem em atos e processos mediados culturalmente. (VYGOTSKI, 1997, p. 347) .

A experiência cultural envolve, indispensavelmente, o individual e o social. A escrita, os símbolos aritméticos etc., são processos ou métodos apreendidos pelo indivíduo, mas são formas culturais especificadas socialmente. Por isso, é necessário identificar com que termos Vigotski concebe desenvolvimento cultural, que relação estabelece com o social, e o que essa relação significa para o entendimento psicológico de atividade simbólica no desenvolvimento humano.

Para Vygotski (1995c), desenvolvimento cultural significa "o domínio de meios externos da conduta cultural e do pensamento, ou o desenvolvimento da linguagem, do cálculo, da escrita, da pintura etc.” (p. 34)9. Mas Vigotski tem uma concepção de Cultura que traz o social como fonte. Para Vygotski (1995b, p. 151), "a cultura é um produto da vida social e da atividade social do ser humano" ${ }^{\text {.10 }}$. Assim, não é exclusivamente individual. Além disso, Vygotski (1995a) afirma que "é a sociedade e não a natureza que

\footnotetext{
${ }^{7}$ Da perspectiva histórico-cultural, ou do estudo do desenvolvimento das funções psíquicas superiores, Vygotski (1995a) comenta que "la que diferencia en primer lugar al hombre de los animales desde el punto de vista psicológico es la significación, es decir, la creación y el empleo de los signos.” (p. 84, grifo do autor). Vygotski (1995a) coloca, pelo princípio da significação, que o signo, como um instrumento psicológico, amplia enormemente o sistema de atividade das funções psíquicas, referindose a ele como um instrumento da atividade bumana. $\mathrm{O}$ autor comenta também que a linguagem é um meio social de comunicação e interação. No livro Pensamiento y Habla, publicado em 1934, Vigotski analisa o significado da palavra como um fenômeno ao mesmo tempo verbal e intelectual, sem ver esses dois âmbitos apenas como aspectos externos da vida psíquica. Vigotski (2012) comenta que o significado da palavra "es la unidad de la palabra y el pensamiento" (p. 426, grifo do autor). Vigotski (2012) comenta que suas investigações corroboram essa afirmação e valida sua tese de que o significado da palavra é a unidade do pensamento discursivo; e que operar com o significado da palavra oferece a possibilidade real de investigação do seu desenvolvimento, considerando que o significado das palavras se desenvolve.

${ }^{8}$ Tradução nossa, livre, de: "El niño aprende a emplear funcionalmente determinados signos como medio para ejecutar tal o cual operación psicológica. De tal manera, las formas elementales y primitivas de conducta se convierten en actos y procesos culturales mediados.” (VYGOTSKI, 1997, p. 347).

${ }^{9}$ Tradução nossa, livre, de: “(...) el dominio de medios externos de la conducta cultural y del pensamiento, o el desarrollo de lenguaje, del calculo, de la escritura, de la pintura etc." (VYGOTSKI, 1995b, p. 34).

${ }^{10}$ Tradução nossa, livre, de: "la cultura es un producto de la vida social y de la atividad social del ser humano". (VYGOTSKI, 1995b, p. 151).
} 
deve figurar em primeiro lugar como o fator determinante da conduta do homem. Nisso consiste toda a ideia de desenvolvimento cultural da criança”" (p. 89) ${ }^{11}$. Nessa discussão, símbolos e signos são vistos como um meio, ou como mediação social. Para Vygotski (2007, p. 160, grifo no original), "todas as coisas culturais são sociais; um signo ou símbolo independente do organismo, como um instrumento, é um meio ou mediação social"12.

Segundo Fichtner (2010), Vigotski afirma que o cultural é derivado do social, e não uma produção independente ou alheia à sociedade e às relações humanas. Para Pino (2005), ao definir cultura como produção humana que tem fonte na vida social e na atividade social do homem, Vigotski ressalta também que ela não é obra da natureza. Para Pino (2005), isso é tratado em Vigotski como sendo a passagem do plano biológico para o plano da cultura, ou como a passagem para o estado da sociedade.

Essas questões também ressoam na discussão da relação entre o desenvolvimento intelectual e o social. Vigotski (2018) destaca o social como fator determinante no desenvolvimento intelectual do indivíduo. Para ele, por ser um ser social, mesmo que uma criança seja intelectualmente talentosa, não desenvolverá plenamente suas qualidades fora das relações sociais, fora da relação com a sociedade, e sem também utilizar das formas e dos métodos elaborados ao longo do desenvolvimento histórico da humanidade, passando de um processo inicial de desenvolvimento para um processo final, ideal, como nos adultos.

A nosso ver, a criança utilizar-se, no curso do seu desenvolvimento intelectual, dos meios e métodos elaborados ao longo do desenvolvimento histórico da humanidade, se aproxima da ideia de desenvolvimento cultural, e de atividades simbólicas, no sentido do domínio das formas simbólicas de expressão, como comentado anteriormente. Se aproxima principalmente da ideia de coexistência das linhas externa e interna da atividade simbólica.

Outro fator importante no desenvolvimento psíquico é a comunicação humana. Segundo Rivière (2002), as funções psíquicas superiores são um resultado da comunicação humana, sem a qual a conduta cultural não se converteria em mediação significativa, em signo. Ao falar das funções psíquicas superiores como sendo de ordem social, Vygotski (1995b, p. 151) comenta: "sua composição, estrutura genética e modo de ação, em uma palavra, toda sua natureza é social; mesmo quando se torna em processos psíquicos segue sendo quase social. O homem, mesmo quando a sós consigo mesmo, conserva funções de comunicação"13. Para Vygotski (2007, p. 160), "geneticamente, as relações sociais, que são relacionamentos reais entre as pessoas, estão na base de todas as funções superiores e de suas relações”'14.

\footnotetext{
${ }^{11}$ Tradução nossa, livre, de: "Es la sociedad y no la naturaleza la que debe figurar en primer lugar como el factor determinante de la conducta del hombre. En ello consiste toda la idea del dessarrollo cultural del niño". (VYGOTSKI, 1995a, p. 89).

12 Tradução nossa, livre, de: “(...) todas las cosas culturales son sociales; un signo o símbolo independiente del organismo, como un instrumento, es un medio o mediación social” (VYGOTSKI, 2007, p. 160, grifo do autor).

13 Tradução nossa, livre, de: "su composición, estrucutura genética y modo de acción, en una palabra, toda su naturaleza es social; incluso al convertirse en procesos psíquicos siegue siendo cuasi-social. El hombre, incluso a solas consigo mismo, conserva funciones de comunicación". (VYGOTSKI, 1995b, p. 151).

${ }^{14}$ Tradução nossa, livre, de: "Genéticamente las relaciones sociales, que son relaciones reales entre las personas, están en la
} 
Fichtner (2010) analisa essas questões da seguinte maneira: "como se transformam as relações sociais em funções psíquicas? A colaboração representa a origem das funções psíquicas superiores. $\mathrm{O}$ ambiente social não é uma condição exterior do desenvolvimento psíquico da criança, ele é a condição interior essencial". (p. 257, grifo do autor). Fichtner (2010) comenta que a "cultura é um produto da vida social e da atividade comunitária dos homens - instrumentos e signos foram feitos para serem meios sociais, órgãos sociais” (p. 256). Vygotski (1995b, p. 146) destaca que o signo (significação) é fundamental na conversação, na comunicação entre as pessoas, na medida em que ele é tanto um meio de relação social e de influência sobre as outras pessoas quanto meio de influência sobre a própria conduta, orientado para os processos psíquicos.

Na análise de Temporetti (2012), para Vigotski, as funções psíquicas não são concebidas como já estando em sua totalidade de forma acabada ou semiacabada no indivíduo, e que no social simplesmente se desenvolvem e se enriquecem ou se inibem e se frustram. Segundo Temporetti (2012), para Vigotski,

o social e a cultura não estão apenas fora do indivíduo, no coletivo ou nos sistemas simbólicos que mudam e se transformam, estão no próprio indivíduo, como sujeito construído e construtor, como produto e produtor de relações sociais historicamente construídas. Essa é uma contradição fundamental que apenas um pensamento materialista e dialético pode compreender completamente" (TEMPORETTI, 2012, p. CXVII) ${ }^{15}$.

Daniels (2003) comenta que, no período final da obra de Vigotski, em que temas como zona de desenvolvimento próximo, desenvolvimento dos conceitos e do conceito científico na infância, entre outros, são representativos, o autor continua usando o método dialético no exame do social e do individual nas tensões entre o biológico, o natural, e as influências sociais, históricas e culturais no desenvolvimento humano.

Dentre as muitas contribuições deixadas por Vigotski em seu livro Pensamiento y Habla, publicado pela primeira vez pouco depois de sua morte em 1934, Vigotski (2012, p. 16-17) ressalta o significado como o aspecto interno da palavra e a unidade que contém em si todas as propriedades inerentes ao pensamento discursivo. Nesse livro, Vigotski (2012) salienta a relação entre o natural e o social, comentando que "o pensamento discursivo não é uma forma natural e espontânea de comportamento, mas uma forma sócio-histórica, e por essa razão se distingue, em essência, por toda uma série de propriedades e regularidades específicas que não estão presentes nas formas naturais de pensamento e fala"16 (p. 166-167, grifo no original).

\footnotetext{
base de todas las funciones superiores y de sus relaciones." (VYGOTSKI, 2007, p. 160).

15 Tradução nossa, livre, de: "Lo social y la cultura no solo están fuera del individuo, en lo coletivo o en los sistemas simbólicos que cambian y se transformam, están en el individuo mismo, como sujeto construido y constructor, como producto y productor de relaciones sociales históricamente construídas. Es esta una contradicción fundamental que solo un pensamiento materialista y dialéctico puede aprehender en toda su magnitud.” (TEMPORETTI, 2012, p. CXVIII).

16 Tradução nossa, livre, de: “(...) el pensamiento discursivo no es una forma natural y espontánea de comportamiento, sino una forma sócio-histórica, y por tal razón se distingue en esencia por toda una serie de propiedades y regularidades específicas que no se hallan presentes en las formas naturales del pensamiento y el habla" (p. 166-167, grifo do autor).
} 


\section{Aspectos psicológicos da atividade simbólica}

Vygotski e Luria (2007) comentam que a atividade simbólica não se constitui como tal por uma mera interferência ou acumulação de hábitos. Para eles, a atividade simbólica tem dois aspectos interligados ou interrelacionados, presentes no desenvolvimento das funções psíquicas superiores. No primeiro aspecto, vem relacionada a uma das leis genéticas de desenvolvimento das funções psíquicas que estipula que cada atividade simbólica no desenvolvimento da criança que se constitui antes de formas sociais e distintivas de cooperação psíquica entre os indivíduos, continua preservada, em seus atributos essenciais, nas funções psíquicas superiores, mudando somente a situação de uso. No segundo aspecto, ela se encontra no caráter indireto das operações psíquicas, visto como o traço específico que caracteriza as funções psíquicas superiores. Esse caráter indireto se coloca na operação com signos que, por sua vez, leva diretamente à compreensão da essência interna dos processos psíquicos superiores.

Mas Vygotski e Luria (2007) frisam que o começo do desenvolvimento cultural da criança não se remete à relação entre signo e significado como se dá com os adultos, e os seus padrões de domínio dessa relação. Para eles, fazer isso é ignorar a complexa história de sua formação interna e esquecer que a vinculação entre a palavra e o objeto é um longo processo dialético e complexo de significação, com viradas e mudanças críticas no curso do desenvolvimento psíquico da criança. Assim, Vygotski e Luria (2007) comentam que analisar o processo do desenvolvimento cultural e seu impacto na formação e desenvolvimento das funções psíquicas superiores implica entender que "as operações com signos são o resultado de um complexo processo de desenvolvimento no pleno sentido da palavra. No começo do processo podem ser observadas formas de transição e mistas que combinam tanto componentes naturais como culturais do comportamento infantil". (VYGOTSKI; LURIA, 2007, p. 64, grifo no original) ${ }^{17}$.

\section{Simbolização e educação escolar: foco na linguagem escrita e na aritmética}

Vygotski e Luria (2007) e Vigotski (2007) comentam que a simbolização não se dá a priori, primária e irredutível, e não é algo fortuito ou independente da realidade e da ação da criança, mas um processo psicológico complexo, vivo, de conscientização do signo na transição e subordinação do objeto ao significado, semanticamente. Os autores comentam que a criança não relaciona o simbólico a certos estímulos por pura lógica ou que a separação do campo da percepção visual do campo do significado é realizada de uma só vez pela criança. Trata-se de um longo processo de desenvolvimento em que a fala

\footnotetext{
17 Tradução nossa, livre, de: "Las operaciones con signos son el resultado de un complejo proceso de desarrollo en el pleno sentido de la palabra. Pueden observarse al principio del proceso formas transicionales y mixtas que conbinan tanto componentes naturales como culturales del comportamiento infantil”. (VYGOTSKI; LURIA, 2007, p. 64, grifo dos autores).
} 
também atua ${ }^{18}$.

O simbólico, a simbolização, no desenvolvimento da criança, não se forma de maneira puramente intuitiva ou intelectualista. A criança não compreende um significado convencional, ou a relação interna entre signo e significado, de maneira intuitiva, como um descobrimento intelectual ou como algo já pronto no puro verbalismo, mas como um gradual e complexo processo de desenvolvimento psíquico, social e cultural, que inclui a relação dialética entre o que é essencial no pensamento concreto e o significado, a comunicação com outras pessoas e a interação ativa da criança com sua realidade e as formas e o conteúdo de sua cultura. As interações sociais, a comunicação, são fatores importantes nesse processo. (VYGOTSKI; LURIA, 2007; VIGOTSKI, 2007, 2012; VYGOTSKI, 1995d, 1995e).

Como essas questões se colocam no âmbito da educação escolar? Luria (2015) comenta que, para Vigotski, a linguagem é o instrumento psicológico que mais se destaca por permitir a organização e o desenvolvimento dos processos do pensamento, colocando como exemplos a escrita e a aritmética. Segundo Luria (2015, p. 49) “a linguagem carrega em si os conceitos generalizados que são o repertório da cultura humana".

Outro fator fundamental é a interação da criança com um adulto mais maduro ou mais experiente. Para Vygotski (2007, p. 161, grifo no original), “no desenvolvimento cultural esta interação é a principal força condutora de todo o desenvolvimento (a aritmética da criança e do adulto, a fala etc.)"119. Nesse sentido, o processo de ensino é muito importante, porque opera dialeticamente e metodicamente com essas formas distintas. Vigotski (2012) compreende o processo de ensino "como uma forma sistemática de cooperação entre o professor e a criança; no curso dessa cooperação as funções psicológicas superiores da criança amadurecem, com a ajuda e a participação do adulto” (p. 268) ${ }^{20}$. Vigotski (2012) comenta também que o desenvolvimento do conceito científico se dá nas condições do ensino.

Os textos de Vigotski, analisados neste trabalho, indicam que desenvolvimento cultural e processo escolar se inter-relacionam formando um momento crítico, não linear, no curso do desenvolvimento psíquico da criança, sendo o desenvolvimento de atividades simbólicas como a escrita, a leitura, o cálculo etc., um de seus aspectos básicos. Nesse processo, a escola formaliza uma reordenação do pensamento, e da linguagem, liberando a criança da situação imediata, conferindo outros significados à sua ação ${ }^{21}$.

Considerando as peculiaridades da linguagem escrita, Vygotski (1995d) toma como base a ideia

\footnotetext{
${ }^{18}$ Por exemplo, Lopes (2010) comenta que, para Vigotski, “o desenho é uma linguagem gráfica que emerge tendo como base a fala, a linguagem verbal. Por isso é muito comum as crianças utilizarem as palavras oralizadas como forma de expressar uma representação" (p. 217). Vygotski e Luria (2007) comentam que a fala não acompanha simplesmente a percepção da criança, mas desempenha um papel ativo desde o princípio, no sentido de que a fala da criança (ou seu discurso) articula sua percepção. 19 Tradução nossa, livre, de: "En el desarrollo cultural esta interacción es la principal fuerza conductora de todo el desarrollo (la aritmética del niño y del adulto, el habla, etcétera)" (VYGOTSKI, 2007, p. 161, grifo do autor).

20 Tradução nossa, livre, de: “(...) como una forma particular de cooperación sistemática entre el pedagogo y el niño; en el transcurso de esta cooperación maduran las funciones psicológicas superiores del niño, con la ayuda e participación del adulto". (VIGOTSKI, 2012, p. 268).

${ }^{21}$ Katuta (2001) comenta que a construção de conhecimentos escolares envolve, como condição, a criação de significados sobre a realidade diferente dos comumente construídos ao longo da vida do sujeito, de modo que eles sejam repensados em outros termos e perspectivas.
} 
de que ela é formada por um "sistema de signos que identificam os sons e palavras da linguagem oral que são, por sua vez, signos de objetos e relações reais.” (VYGOTSKI, 1995d, p. 184) ${ }^{22}$. A linguagem oral seria o nexo intermediário, e a linguagem escrita um sistema de signos que simbolizam diretamente os objetos designados, e suas relações. Mas Vygotski (1995d) comenta que, na psicologia, seu desenvolvimento vinha sendo pouco estudado "como um sistema de símbolos e signos cujo domínio significa uma virada crítica em todo o desenvolvimento cultural da criança." (VYGOTSKI, 1995d, p. 184) ${ }^{23}$. Vygotski (1995d) ressalta que “o domínio da linguagem escrita significa, para a criança, dominar um sistema de signos simbólicos extremamente complexo" (p. 184) ${ }^{24}$.

Para Vygotski (1995d, p. 184-185), o desenvolvimento da linguagem escrita não é algo que simplesmente vem de fora, e sem nenhum nexo de continuidade com formas em curso, ou anteriores, de desenvolvimento da criança. Para o autor, como todo processo de desenvolvimento cultural, trata-se de uma conduta que surge em um determinado ponto do desenvolvimento da criança, vinculado geneticamente com tudo aquilo que o preparou e o fez possível. Esse momento decisivo no desenvolvimento não é determinado unicamente pelo ensino escolar, mas resultado de um longo desenvolvimento das funções psíquicas superiores do comportamento infantil, e de nexos e interações entre formas antigas e novas.

Para Vygoski (1995d, p. 185-188), o gesto representativo é o primeiro signo visual que contém a futura escrita da criança, e que envolve a formação do nexo genético entre o gesto e o signo escrito, a ser desenvolvido com o tempo. Outros momentos ou nexos que levam à linguagem escrita são: o desenho e a brincadeira infantil. O desenho é visto como representação simbólica e gráfica por meio do gesto, e como expressão motora da psique. No rabisco, a criança pequena complementa com um gesto o desenho feito num papel: "quando quer desenhar um salto, faz movimentos de saltar com a mão e deixa as marcas desse movimento no papel" (VYGOTSKI, 1995d, p. 187) ${ }^{25}$. Na brincadeira, ou melhor, na função simbólica da brincadeira infantil, objetos passam a significar outros, que se convertem em seus signos. Um pedaço de madeira se converte em um bebê durante a brincadeira, porque permite que sejam feitos os mesmos gestos que representam a nutrição e outros cuidados maternos: "o próprio movimento da criança, seu próprio gesto, que atribui a função do signo ao objeto correspondente, que confere sentido. Toda atividade simbólica representacional está cheia desses gestos indicadores" (VYGOTSKI, 1995d, p. $187-188)^{26}$.

\footnotetext{
${ }^{22}$ Tradução nossa, livre, de: “(...) sistema de signos que identifican convencionalmente los sonidos y las palabras de lenguajem oral que son, a su vez, signos de objetos y relaciones reales” (VYGOTSKI, 1995d, p. 184).

${ }^{23}$ Tradução nossa, livre, de: “(...) como un sistema de símbolos y signos cuyo dominio significa un viraje crítico en todo el desarrollo cultural del niño." (VYGOTSKI, 1995d, p. 184).

${ }^{24}$ Tradução nossa, livre, de: "El dominio del lenguaje escrito significa para el niño dominar un sistema de signos simbólicos extremamente complejo" (VYGOTSKI, 1995d, p. 184).

25 Tradução nossa, livre, de: "Cuando quiere dibujar un salto, hace movimientos de saltar con la mano y deja huellas de ese movimiento en el papel” (VYGOTSKI, 1995d, p. 187).

${ }^{26}$ Tradução nossa, livre, de: "Es el propio movimiento del niño, su propio gesto, los que atribuyen la función del signo al objeto correspondiente, lo que confiere sentido. Toda la actividad simbólica representacional está llena de esos gestos
} 
Para Vygotski (1995d), assim como no desenho ou no rabisco infantil, a brincadeira é um sistema complexo de linguagem informado mediante gestos, que assinala o significado dos diversos jogos simbólicos que nela se desenvolve. A conversão em signo independente se dá graças à atribuição de significado que reside no gesto. Na criança um pouco maior, além de gesticular, ela fala, explica para si mesma a brincadeira, a organiza. Para o autor, a designação verbal convencional dos objetos forma uma conexão linguística de muita riqueza, que explica e confere sentido a cada movimento, objeto e ação, em separado. A passagem desses momentos para a escrita, é um processo único, em essência.

A linguagem escrita é entendida através da oral, mas essa mudança vai diminuindo pouco a pouco; o elo intermediário, que é a linguagem oral, desaparece e a linguagem escrita se torna diretamente simbólica, percebida da mesma maneira que a linguagem oral. Basta imaginar a imensa mudança que se produz em todo o desenvolvimento cultural da criança, graças ao seu domínio da linguagem escrita, graças a possibilidade de ler e, por conseguinte, enriquecer-se com todas as criações da genialidade humana no campo da palavra escrita, para compreender o momento decisivo que a criança vive quando descobre a escrita. (VYGOTSKI, 1995d, p. 197-198)27.

Para Vygoski (1995d), a aprendizagem da linguagem escrita é um processo intencional e motivado que significa, para a criança, dominar um sistema de signos complexos, sob a orientação e colaboração do professor. De modo semelhante, Vygotski (1995e) comenta que o desenvolvimento das operações aritméticas reflete uma virada ou mudança de uma "aritmética natural" desenvolvida pela criança em sua relação espontânea, direta, com os objetos, para a aritmética cultural ensinada na escola (mediada culturalmente). Vygotski (1995e) comenta que a aprendizagem escolar, ou formal, de um sistema de cálculo desenvolvido pela humanidade, como formas abstratas especiais, representa a última etapa do desenvolvimento da aritmética. Essa passagem não é linear, mas um momento crítico no desenvolvimento da criança, no qual, sob a orientação e colaboração do professor, ela "começa a dominar os signos, os números, as regras de sua designação, regras que nós utilizamos e que consistem em substituir as operações com objetos por operações com sistemas numéricos." (VYGOTSKI, 1995e, p. $209)^{28}$.

Vygotski (1995e) comenta que é importante compreender que a aritmética escolar constitui um momento de mudança no desenvolvimento da criança, e que essa mudança crítica se dá com o aprendizado e domínio de mediações simbólicas convencionais mais desenvolvidas que resultam, com o

\footnotetext{
indicadores" (VYGOTSKI, 1995d, p. 187-188).

27 Tradução nossa, livre, de: "El lenguaje escrito se compreende a través del oral, pero ese cambio se va acortando poco a poco; el eslabón intermedio, que es el lenguaje oral, desaparece y el lenguaje escrito se hace directamente simbólico, percebido del mismo modo, que el lenguaje oral. Basta con imaginarse el inmenso viraje que se produce en todo el desarrollo cultural del niño gracias a su dominio del lenguaje escrito, gracias a la posibilidad de leer y por consiguiente, enriquecerse con todas las creaciones del genio humano en el terreno de la palabra escrita para comprender el momento decisivo que vive el niño cuando descubre la escritura" (VYGOTSKI, 1995d, p. 197-198).

28 Tradução nossa, livre, de: “(...) empieza a dominar los signos, las cifras, las reglas de su designación, reglas que nosotros utilizamos y que consisten em sustituir las operaciones con objetos por operaciones com sistemas numéricos." (VYGOTSKI, 1995e, p. 209).
} 
sistema de cálculo, numa etapa nova e ulterior no seu desenvolvimento: “a criança entende o caráter limitado de sua aritmética ao passar para a aritmética mediada"29.

Para Vygotski (1995e), sem a aritmética escolar, ou sem essa etapa ulterior de desenvolvimento das operações aritméticas via domínio de símbolos e signos convencionais, "não podemos dizer por que vias seguiria o desenvolvimento ulterior da criança deixado por sua própria vontade." (VYGOTSKI, 1995e, p. 209) ${ }^{30}$. Vygotski (1995f, p. 315-316) comenta que, na escola, no terreno da aritmética cultural, as crianças solucionam problemas diversos com métodos e conhecimentos similares, enquanto no processo da aritmética "natural" ou primária, o desenvolvimento tem muito mais variações e formas.

Com relação à escrita, Vygotski (1995d) ressalta que é preciso que ela seja tão vital como é a aritmética. Para o autor, a linguagem escrita é um complexo procedimento da conduta cultural que começa, de fato, antes de a criança ter um lápis em suas mãos, na escola. Para ele, o ensino da linguagem escrita é mais do que ensinar a criança a dominar os mecanismos da leitura e da escrita, ou mais do que formar nela hábitos de escrita. A criança deve saber escrever e expressar por escrito os seus pensamentos. A escrita deve ter sentido para ela, ser uma tarefa vital, imprescindível, em seu desenvolvimento, como uma complexa atividade cultural. E então "teremos certeza de que se desenvolverá na criança não como um hábito de mãos e dedos, mas como um tipo realmente novo e complexo de linguagem" (VYGOTSKI, 1995d, p. 201) $)^{31}$.

Como se pode notar nas discussões e citações anteriores, o desenvolvimento cultural, e o processo escolar, não significa a supressão do natural pelo cultural, mas uma mudança no processo do desenvolvimento. Representa, para a criança, uma mudança interna, crítica, não linear, não mecânica, no curso do seu próprio desenvolvimento psíquico.

Vygotski e Luria (2007, p. 45-48) comentam que a inclusão da palavra ou outro símbolo entre os pontos inicial e final de uma ação, de maneira intencional, deliberada ou motivada, é o que determina que um processo psíquico seja superior; e que recorrer ao signo e conferir à ação um caráter mediado, é o que distingue os processos psíquicos mais desenvolvidos ou superiores. Os autores comentam que o emprego de signos é o tipo de operação simbólica superior, originado em condições específicas do desenvolvimento social, que estabelece uma relação especial entre um estímulo e um signo.

\section{Comentários finais}

No campo da Psicologia da Educação, Davis e Oliveira (2010) comentam as aprendizagens

\footnotetext{
${ }^{29}$ Tradução nossa, livre, de: “(...) el niño llega a comprender el carácter limitado de su aritmética y comienza a pasar a la aritmética mediada” (VYGOTSKI, 1995e, p. 211).

30 Tradução nossa, livre, de: “(...) no podemos decir por qué vías habría seguido el ulterior desarrollo del niño dejado a su propio albedrío.” (VYGOTSKI, 1995e, p. 209).

${ }^{31}$ Tradução nossa, livre, de: “(...) estaremos seguros de que se desarrollará en el niño no cómo un hábito de sus manos y dedos sino como un tipo realmente nuevo y complejo de lenguaje.” (VYGOTSKI, 1995d, p. 201).
} 
escolares fundamentais (escrita, leitura e cálculo) da seguinte maneira:

quando a criança passa a frequentar a escola, ao aprender a ler, a escrever e a manejar números, ela está apropriando-se de toda uma experiência humana-social que levou séculos para ser construída e que está sendo continuamente modificada pelo conjunto dos homens. (DAVIS; OLIVEIRA, 2010, p. 91)

Com relação à aprendizagem, Davis e Oliveira (2010) comentam que ela não se trata de um processo exclusivamente individual, isolado, na criança, porque, para aprender, ela precisa interagir com outras pessoas, ampliando suas formas de lidar com o mundo, significar suas ações e formar conceitos, integrando pensamento e linguagem; "que a aprendizagem é o processo por meio do qual a criança se apropria ativamente do conteúdo da experiência humana, daquilo que o seu grupo social conhece” (p. 26); e que para entender esse processo em sua extensão é preciso reconhecer a natureza social da aprendizagem.

Como trabalhado neste texto, para Vigotski, essas questões apontadas por Davis e Oliveira (2010) estariam integrando o desenvolvimento das funções psíquicas superiores, o desenvolvimento cultural da criança, com especial atenção para as linhas externas e internas de desenvolvimento das atividades simbólicas. O signo tem um papel central nesse desenvolvimento. Essas questões estariam também ligadas à importância que Vigotski confere à comunicação humana, as interações sociais, no processo de significação dos objetos e das ações, no desenvolvimento psicológico da criança, em geral, e no processo de aprendizagem escolar, em particular.

No âmbito educacional, para Vigotski, todo esse processo significa que, na escola, a criança apreenderá formas novas de simbolização, ou sistemas de representação e de conceituação de objetos e da realidade, no processo de ensino, reordenando seu pensamento.

Ao mesmo tempo, é preciso reconhecer que, na escola, o desenvolvimento da criança terá um direcionamento específico, uma forma de regulação. Dando como exemplo a escrita, Vygotski (1995f) comenta: "o caminho para dominar a escrita se encontra no marco da idade escolar e está sujeito à influência sistemática da educação e do desenvolvimento cultural” (p. 316) ${ }^{32}$. Essa influência sistemática e essa sujeição, também devem ser discutidas e refletidas.

Em suma, os textos analisados neste trabalho mostraram que a leitura, a escrita, o cálculo etc., são atividades simbólicas do desenvolvimento cultural, que a criança passa a conhecer na escola, e cujo domínio representa uma mudança crítica no curso do seu desenvolvimento psicológico. Essa conduta cultural que a criança passa a conhecer na escola, envolve o desenvolvimento do pensamento, do aspecto semântico da fala, transformando os vínculos psíquicos da criança com a realidade objetiva, com o mundo, e com ela mesma.

Vigotski nos mostra que é indispensável atentar para a natureza simbólica humana, concebendo-

\footnotetext{
32 Tradução nossa, livre, de: “(...) el camino para dominar la escritura se encuentra en el marco de al edad escolar y se halla sometida a la sistemática influencia de la educación y del desarrollo cultural” (VYGOTSKI, 1995f, p. 316).
} 
se a criança como um ser social, porém ativo, dialético, que desenvolve na escola, de maneira sistemática, convencional, atividades simbólicas, e o pensamento, mas que é também capaz de expressar sua compreensão das coisas, e seus sentimentos e motivações.

Em última instância, deve-se reconhecer também, na natureza simbólica humana, a questão da consciência da realidade, e seu papel na formação humana, analisando a atividade simbólica da escrita, da leitura, do cálculo etc., e o saber que elas compreendem, no plano da formação da personalidade e expressão da consciência sobre o mundo.

Segundo Cheptulin (2004), a consciência não reflete a realidade de maneira passiva, como no espelho, mas de maneira ativa e criativa, no decorrer da transformação prática da realidade. Cheptulin (2004) comenta que a consciência não é todo o saber, no entanto a relação entre consciência e saber se determina, no processo de pensamento, a partir da elaboração do que se compreende de uma situação concreta, sendo o saber representado pelo conjunto de conhecimentos sobre a realidade, do qual dispõe a sociedade humana. É preciso acrescentar que "a consciência existe não apenas sob a forma de conhecimentos, mas igualmente sob a forma de emoções, sentimentos, vontade etc." (CHEPTULIN, 2004, p. 99).

Os textos de Vigotski, analisados neste trabalho, indicam que a atividade simbólica deve ser compreendida como uma parte viva da totalidade da vida humana concreta, das relações sociais, da comunicação humana, do desenvolvimento psicológico da criança e do conhecimento. Essa discussão implica pensar a atividade simbólica na interrelação dialética e complexa entre ensino-aprendizagem, conhecimento escolar, significação social da realidade e desenvolvimento psíquico e cultural da criança. De modo abrangente, pensá-la na educação e na vida como parte da construção de uma sociedade mais humana e mais justa.

\section{REFERÊNCIAS}

CHEPTULIN, Alexandre. A Dialética Materialista: categorias e leis da dialética. Trad. por Leda Rita Cintra Ferraz. São Paulo: Editora Alfa-Ômega, 2004.

COSTA, Eduardo Moura da; MARTINS, João Batista. O projeto Vigotskiano para uma psicologia científica: anotações sobre o "Significado Histórico da Crise da Psicologia". Avances en Psicología Latinoamericana, Bogotá, Colômbia, v. 36, n. 3, p. 537-551, 2018.

DANIELS, Harry. Vygotski e a Pedagogia. Trad. por Milton Camargo Mota. São Paulo: Edições Loyola, 2003.

DAVIS, Claudia; OLIVEIRA, Zilma de Moraes Ramos de. Psicologia na Educação. 3 ed. São Paulo: Cortez, 
2010.

DUPAS, Giselle; OLIVEIRA, Irma de; COSTA, Teresa Neumann Alcoforado. A importância do interacionismo simbólico na prática da enfermagem. Revista da Escola de Enfermagem da Universidade de São Paulo - USP, São Paulo, v. 31, n. 2, p. 219-226, ago. 1997.

EAGLETON, Terry. A Ideia de Cultura. Trad. por Sandra Castello Branco. São Paulo: Editora UNESP, 2005.

FICHTNER, Bernd. Instrumento - Signo - Mímesis: o pontecial de "representações simbólicas" na perspectiva da abordagem histórico-cultural. In: SILVA, Léa Stahlschimidt Pinto; LOPES, Jader Janer Moreira (orgs.). Diálogos de Pesquisas sobre Crianças e Infâncias. Niterói-RJ: Editora da UFF, 2010, p. 261-268.

KATUTA, Angela Massumi. Representação do espaço vivido, percebido, imaginário e concebido. Revista Boletim de Geografia, Universidade Estadual de Maringá, Paraná, v. 10, n. 2, p. 179-186, 2001.

KOZULIN, Alex. O conceito de atividade na psicologia soviética: Vygotsky, seus discípulos, seus críticos. In: DANIELS, Harry (org.). Uma Introdução a Vygotsky. Trad. por Marcos Bagno. São Paulo: Edições Loyola, 2002.

LOPES, Jader Janer Moreira. Cartografia com crianças: "Atlas da Creche UFF". In: SILVA, Léa Stahlschimidt Pinto; LOPES, Jader Janer Moreira (orgs.). Diálogos de Pesquisas sobre Crianças e Infâncias. Niterói-RJ: Editora da UFF, 2010, p. 211-226.

LURIA, Alexander R. A Construção da Mente. 2 ed. Trad. por Marcelo Brandão Cipolla. São Paulo: Ícone, 2015.

MARTINS, Lígia Márcia. O desenvolvimento do psiquismo e a educação escolar: contribuições à luz da psicologia histórico-cultural e da pedagogia histórico-crítica. Tese (para obtenção de título de LivreDocente em Psicologia da Educação) - Faculdade de Ciências da Universidade Estadual Paulista, UNESP, Baurú, São Paulo, 2011, 249 f.

OSUCCI, Rosamaria Schlatter; SAITO, Heloísa Toshie Irie. Teoria histórico-cultural como princípio educativo. In: PARANÁ, Secretaria de Estado da Educação. Superintendência de Educação. O professor PDE e os Desafios da Escola Pública Paranaense, 2010. Curitiba: SEED/PR, 2014, p. 1-21, v. 1.

PINO, Angel. As Marcas do Humano: as origens da constituição cultural da criança na perspectiva de Lev S. Vigotski. São Paulo: Cortez, 2005.

RIVIÈRE, Angel. La Psicología de Vigotski. Madrid: A. Machado Libros, 2002.

TEMPORETTI, Félix. Introducción. El retorno del hijo prodigioso. In: VIGOTSKI, Lev S. Pensamiento y Habla. Trad. por Alejandro Ariel González. Buenos Aires: Colihue, 2012, p. LXXXVII-CXXV.

VIGOTSKI, Lev S. Quarta aula. O problema do meio na pedologia. In: VIGOTSKI, Lev S. Sete Aulas de Vigotski sobre os Fundamentos da Pedologia. Trad. por Zoia Prestes, Elizabeth Tunes e Cláudia da Costa Guimarães Santana. Rio de Janeiro: E-Papers, 2018, p. 73-91.

VIGOTSKI, Lev S. Pensamiento y Habla. Trad. por Alejandro Ariel González. Buenos Aires: Colihue, 2012.

VIGOTSKI, Lev S. O papel do brinquedo no desenvolvimento. In: VIGOTSKI, Lev S. A Formação Social da Mente: o desenvolvimento dos processos psicológicos superiores. Trad. por José Cipolla Neto, Luís Silveira Menna Barreto e Solange Castro Afeche. São Paulo: Martins Fontes, 2007, p. 125-148. 
VYGOTSKI, Lev S. Psicología humana concreta. In: del RÍO, Pablo; ÁLVAREZ, Amelia (edit.). Escritos sobre Arte e Educación Creativa de Lev S. Vygotski. Trad. por Pablo del Río e Amelia Álvarez. Madrid: Fundación Infancia y Aprendizaje, p. 155-172, 2007.

VYGOTSKI, Lev S. Anomalías del desarrollo cultural del niño. In: VYGOTSKI, Lev S. Materiales tomados de Intervencines, Informes, Etcétera - Obras Escogidas: Madrid: A. Machado Libros, Tomo V, 1997, p. 347.

VYGOTSKI, Lev S. Método de investigación. In: VYGOTSKI, Lev S. História del Desarrollo de las Funciones Psíquicas Superiores - Obras Escogidas. Trad. por Lydia Kuper. Madrid: Visor, Tomo III, 1995a, p. 47-96.

VYGOTSKI, Lev S. Génesis de las funciones psíquicas superiores. In: VYGOTSKI, Lev S. História del Desarrollo de las Funciones Psiquicas Superiores - Obras Escogidas. Trad. por Lydia Kuper. Madrid: Visor, Tomo III, 1995b, p. 139-168.

VYGOTSKI, Lev S. El problema del desarrollo de las funciones psíquica superiores. In: VYGOTSKI, Lev S. História del Desarrollo de las Funciones Psíquicas Superiores - Obras Escogidas. Trad. por Lydia Kuper. Madrid: Visor, Tomo III, 1995c, p. 11-46.

VYGOTSKI, Lev S. La prehistoria del desarrollo del lenguaje escrito. In: VYGOTSKI, Lev S. História del Desarrollo de las Funciones Psíquicas Superiores - Obras Escogidas. Trad. por Lydia Kuper. Madrid: Visor, Tomo III, 1995d, p. 183-206.

VYGOTSKI, Lev S. Desarrollo de las operaciones artiméticas. In: VYGOTSKI, Lev S. História del Desarrollo de las Funciones Psiquicas Superiores - Obras Escogidas. Trad. por Lydia Kuper. Madrid: Visor, Tomo III, 1995e, p. 207-212.

VYGOTSKI, Lev S. El problema de la edad cultural. In: VYGOTSKI, Lev S. História del Desarrollo de las Funciones Psíquicas Superiores - Obras Escogidas. Trad. por Lydia Kuper. Madrid: Visor, Tomo III, 1995f, p. 315-325.

VYGOTSKI, Lev S.; LURIA, Alexander R. El instrumento y el Signo en el Desarrollo del Niño. Trad. por Pablo del Río. Madrid: Fundación Infancia y Aprendizaje, 2007.

ZAGO, Luis Henrique. O método dialético e a análise do real. Kriterium, Belo Horizonte, n. 127, p. 109124, jun. 2013.

Recebido em: 16 de maio de 2020. Aprovado em: 08 de junho de 2020. 